\title{
Probiotic Supplementation and Its Effect on Weight and Feed tolerance in Preterm Low Birth Weight Newborns: A Clinical Trial
}

\author{
SADEKA CHOUDHURY MONI ${ }^{1}$, M.A. MANNAN² ${ }^{2}$ SANJOY KUMER DEY ${ }^{3}$, ARJUN CHANDRA DEY ${ }^{4}$, \\ DEBASHISH SAHA ${ }^{5}$, MOHAMMOD SHAHIDULLAH ${ }^{6}$
}

\begin{abstract}
:
Background: Establishment of full enteral feed is a major challenge in the care of preterm low birth weight (LBW) neonates. Probiotics are live microbial supplements that colonize preterm bowel with favourable flora, improve tolerance to feed and promotes growth of these premies.
\end{abstract}

Objective: To determine the effect of probiotic supplementation on feed tolerance, postnatal weight gain, duration of hospital stay in preterm low birth weight babies.

\begin{abstract}
Methods : This prospective clinical trial was conducted in the Neonatal Intensive Care Unit (NICU), Bangabandhu Sheikh Mujib Medical University, (BSMMU) from February, 2012 to November, 2012. A total of 65 preterm, low birth weight ( LBW) newborns were included in this study. A multistrain probiotic suspension was given once daily to the infants in probiotic group along with expressed breast milk (EBM) through the nasogastric tube/dropper from the first day of feed which was continued till attainment of full feed. Those in controls received only expressed breast milk. Weight, feed volume increment, features of intolerance were followed up daily. Relevant investigations were done whenever indicated.
\end{abstract}

Results: The mean time to reach full enteral feed in probiotic and control group was $13.71 \pm 3.4$ vs $16.53 \pm 6.13 ; p<0.05$. But weight gain was not affected by supplementation. Hospital stay was shorter in supplemented group.

Conclusion: Probiotic supplementation in preterm low birth weight babies improves feed tolerance and decreases hospital stay but does not affect weight gain.

Key Words: Probiotic, low birth weight, feed tolerance.

\section{Introduction}

Establishment of enteral feed with breast milk optimizes early growth in preterm low birth weight neonates. ${ }^{1}$ But poor tolerance to oral feed, prolonged dependency on parenteral nutrition, necrotizing enterocolitis (NEC), prolonged hospital stay and nosocomial sepsis are frequenly encountered difficulties that cost significant morbidities and mortalities in these tiny newborns.

Worldwide estimate of pre-term birth ranges $5 \%-18 \%{ }^{2}$ The prevalence of LBW in Bangladesh is $36 \%{ }^{3}$

1. Assistant Professor, Department of Neonatology, BSMMU.

2. Professor, Department of neonatology, BSMMU.

3. Associate Professor, Department of neonatology, BSMMU.

4. Associate Professor, Department of neonatology, BSMMU.

5. Medical officer, Department of Paediatrics, BSMMU.

6. Professor \& Chairman,Department of neonatology, BSMMU.

Correspondence: Dr Sadeka Choudhury Moni, E-mail: sadeka. moni.08@gmail.com
Therefore feeding management is an emerging challenge for those involved in neonatal care.

Colonization of the sterile gastrointestinal tract starts immediately after birth and is well established with predominant strains of Bifidobacterium and Lactobacillus within the first few days of life in healthy breastfed infants. ${ }^{4}$ The early pattern of microbial colonisation probably contributes to normal gut development. ${ }^{5-11}$

Preterm infants acquire colonizing bacteria from the intensive care environment rather than their mother's vaginal canal, skin surface and milk. ${ }^{12}$ Therefore their immature gut harbor potentially harmful pathogens like Klebsiella, Enterobacter and Citrobacter species. ${ }^{13}$ Physiological immaturity as well as abnormal pattern of colonization underlie the pathogenesis of various gastrointestinal morbidities ranging from simple 
prematurity related feed intolerence to fulminant necrotizing enterocolitis.

One way to encourage bowel colonisation with "desirable" flora is through the administration of probiotic bacteria. Probiotics are defined as live microorganisms, which when administered in adequate amount may confer health benefits on people with specific illnesses. ${ }^{14}$ Russian scientist and Nobel laureate Élie Metchnikoff, in the beginning of the 20th century suggested to modify gut flora and replace harmful microbes with useful microbes. ${ }^{15}$

Probiotic feeding in preterm reduces the bowel reservoir of more pathogenic species, improves enteral nutrition, and reduces dependence on intravenous nutrition, improves gut mucosal barrier to bacteria and bacterial products, and upregulates protective immunity. Thus use of probiotics leads to improvements in nutrition, a reduction in the incidence of sepsis and use of antibiotics, and prevention of neonatal NEC. ${ }^{16}$

In Bangladesh, with improved obstetric and neonatal care increasing number of preterm babies are surviving. Therefore feeding care and promoting growth are emerging concern for the neonatologists. No conclusive data on use of probiotics in the care of preterm newborns are available in Bangladesh.

The objectives of the study were to determine the effect of probiotic supplementation on feed tolerance, postnatal weight gain and duration of hospital stay in preterm, low birth weight babies.

\section{Materials and Methods}

This was a randomized controlled clinical trial carried out in the department of neonatology, Bangabandhu Sheikh Mujib Medical University (BSMMU), Dhaka, from February 2012 to November 2012. The study protocol was approved by the Institutional Review Board (IRB), BSMMU. The study population was preterm, LBW newborns admitted in NICU, BSMMU during that period. Inclusion criteria were gestational age $<34$ weeks and birth weight $1000-<1800$ gram, able to take enteral feed by 5 days after birth and those for whom informed parental consent was obtained. Babies with major chromosomal syndrome, gastrointestinal anomalies, newborns with severe perinatal asphyxia, newborns with severe IUGR and those with evidence or clinical suspicion of sepsis before randomization were excluded from the study.

After getting informed consent enrolled infants were randomly allocated to either probiotic group or control group. A detailed history was taken from the mother / caregiver and from obstetric record and entered in the structured questionnaire. Gestational age was determined by best obstetric estimates and by modified Ballard score.

Probiotic product used in this study was TS6 Probiotic + manufactured by TENSAL BIO-TECH CO. LTD and the country of origin was Taiwan. One probiotic sachet contained 8 viable probiotic strains belonging to genera Lactobacillus and Bifidobacterium ( 20 billion / 2 gram). This product was tested in the microbiology lab for viability of the microorganism prior to its use.

Trophic enteral feeding was started when vitals were stable, bowel sound audible, no abdominal distension observed and no blood or bile retun by nasogastric suction. A nasogastric tube of size $5 \mathrm{Fr}$ or $6 \mathrm{Fr}$ was introduced following the standard procedure and its position was verified. Probiotic suspension was reconstituted just before administering to the neonates by dissolving the content of a sachet in $6 \mathrm{ml}$ of sterile water taken in a capped clean test tube. Probiotic fortified group received a probiotic mixture ( lactobacillus \& bifidus) along with expressed breast milk through nasogastric tube or dropper once daily from the first feed. The volume of probiotic suspension was $0.5 \mathrm{ml}$ at the start and then increased to $1 \mathrm{ml}$ when feed volume reaches $2 \mathrm{ml} /$ feed. One $\mathrm{ml}$ of the reconstituted supplement contained $3.3 \times 10^{9} \mathrm{CFU}$. In neonates receiving antibiotics, probiotic was administered 2 hours after antibiotics during subsequent feed. Supplementation was continued till attainment of full enteral feed. The neonates in control group were fed breast milk only as per existing protocol. The amount of feeding in either group was advanced slowly if tolerated with no more than a $20 \mathrm{ml} / \mathrm{kg}$ increment per day. All other existing clinical management protocols, clinical practices were uninterrupted.

The neonates in both the groups were followed up clinically; daily weight was taken for all newborns and recorded in the weight chart. All newborns were monitored for clinical signs of sepsis. ${ }^{17}$ Gastrointestinal symptoms such as vomiting, abdominal distension, character of nasogastric aspirate, characteristics of feces and its colour were monitored twice daily and recorded in the case recording sheet. Probiotic supplementation was withheld when feed was withheld for any reason as decided by the consultants and supplementation resumed when enteral feeding was restarted.

Relevant investigations were sent in either group whenever necessary : blood culture and sensitivity, complete blood count (CBC), CRP, peripheral blood 
film (PBF), plain x-ray abdomen, stool for occult blood test (OBT), others as demanded by clinical condition.

Weight gain pattern in the two groups were assessed by statistical difference of Mean \pm SD of birth weight and weight at discharge in two groups.

Time to reach full feeding was calculated by the difference between the age in days at the start of feed and the age of adequate breast feeding or getting $150 \mathrm{ml} / \mathrm{kg} /$ day of requirement of feed by nasogastric tube or dropper.

Outcome measures were weight gain pattern, number of days required to reach full enteral feeding, length of hospital stay.

\section{Data collection and analysis}

Data were collected by structured questionnaire and were processed and analyzed using Microsoft Excel Version 7. Two groups were compared using unpaired student t-test for continuous variables and proportion (Z) test for categorical variables; Values were expressed for mean and standard deviation and percentage. $p$ value $<0.05$ was considered significant.

\section{Results}

A total of 65 preterm newborns were included as study group according to the inclusion criteria. Thirty of them were randomly allocated to Probiotic group and 35 of them to control group. Two newborns in probiotics and 6 from controls died before completion of trial. So 28 neonates in probiotics and 29 from controls were discharged after trial completion. (Fig.-1) and final analysis included these newborns.

The mean \pm SD of gestational age in probiotics group and control group was $31.9 \pm 1.32$ weeks and 32.04 \pm 1.26 weeks respectively. Seventy nine percent of newborns in probiotics group and $83 \%$ of control group were delivered by LUCS (lower uterine caesarean section) and male to female ratio was almost identical. (Table-1)

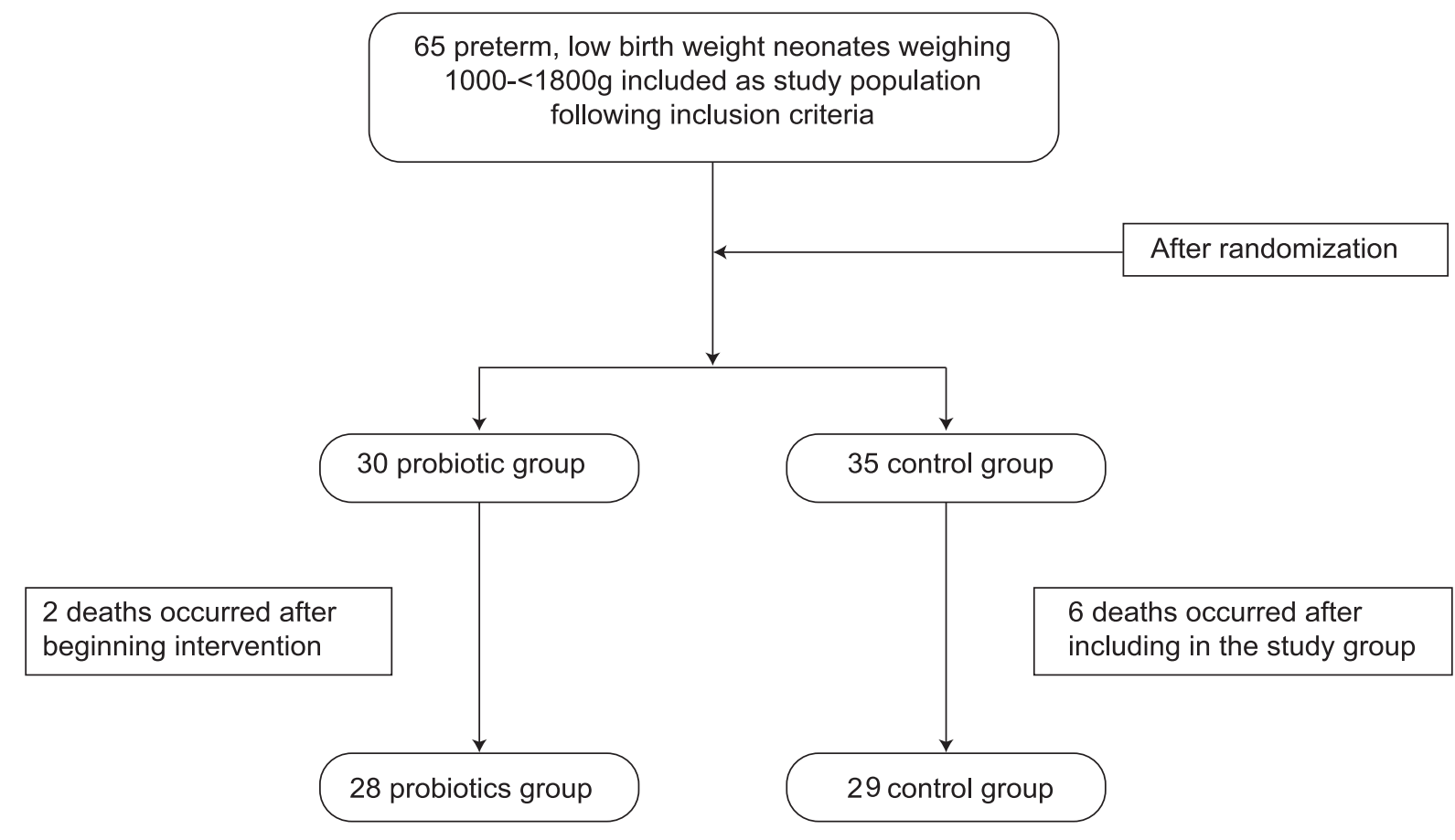

Table -I

Baseline characteristics of the study neonates

\begin{tabular}{lccc}
\hline Characters & $\begin{array}{c}\text { Probiotics Group } \\
(\mathrm{n}=28)\end{array}$ & $\begin{array}{c}\text { Control Group } \\
(\mathrm{n}=29)\end{array}$ & $\begin{array}{c}p \\
\text { value }\end{array}$ \\
\hline Gestationa age (week)Mean $\pm \mathrm{SD}$ & $31.9 \pm 1.32$ & $32.04 \pm 1.26$ & $0.76^{\mathrm{NS}}$ \\
Vaginal Delivery [n (\%)] & $6(21.4)$ & $5(17.2)$ & $0.6^{\mathrm{NS}}$ \\
Caesarean Delivery [n (\%)] & $22(78.6)$ & $24(82.7)$ & $0.6^{\mathrm{NS}}$ \\
Male :Female & $1.5: 1$ & $1.6: 1$ & \\
\hline
\end{tabular}

NS=Not significant, $p$ value reached form unpaired 't'test and $z$ proportion test 
Table-II

Characteristics of enteral feeding of low-birth-weight preterm infants in the probiotics and control groups

\begin{tabular}{lccc}
\hline Feeding characteristics & Probiotics Group $n=28$ & Control Group $n=29$ & $p$ value \\
\hline Start of feed (Mean days $\pm S D$ ) & $2.23 \pm 0.68$ & $2.54 \pm 0.82$ & 0.45 \\
Time to reach full enteral feed (Mean days $\pm S D$ ) & $13.71 \pm 3.4$ & $16.53 \pm 6.13$ & $0.04^{S}$ \\
\hline
\end{tabular}

$\mathrm{S}=$ significant, $p$-value reached form unpaired ' $\mathrm{t}$ ' test.

Table-III

Outcome of Neonates in the Probiotic and Control Group

\begin{tabular}{lccc}
\hline Outcome Measures & Probiotics Group n=28 & Control Group n=29 & $p$-value \\
\hline Discharge Weight (Mean gram \pm SD) & $1458.83 \pm 209.70$ & $1363.86 \pm 216.23$ & $0.07^{N S}$ \\
Duration of hospital stay (Mean days \pm SD) & $19.3 \pm 5.6$ & $23.5 \pm 8.3$ & $0.015^{\mathrm{s}}$ \\
\hline
\end{tabular}

NS=Not significant, $S=$ significant, $p$ value reached from proportion $(Z)$ test and unpaired t-test

Mean days \pm SD of starting feed in probiotics group and control were $2.23 \pm 0.68$ and $2.54 \pm 0.82$ respectively which was not significant statistically but probiotic supplemented neonates reached full feed earlier which was statistically significant $(13.71 \pm 3.4$ vs $16.53 \pm 6.13, p<0.05$ ). (Table-II).

Discharge weight did not differ significantly in the two groups (1458.83 g \pm 209.70 vs $1363.86 \mathrm{~g} \pm$ 216.23). Mean days \pm SD of hospital stay between the two groups was significantly different $(p<0.05)$. In probiotic group mean \pm SD of hospital stay was $19.3 \pm 5.6$ and it was $23.5 \pm 8.3$ in control group. (Table III).

\section{Discussion}

Probiotic supplementation contributes to normal gut development through enhancement of the mucosal protective barrier, ${ }^{5,6}$ modification of systemic immune responses, ${ }^{7-9}$ competitive exclusion of less desirable microbes, ${ }^{10}$ protein and carbohydrate degradation, vitamin and butyrate production, and perhaps also mucosal differentiation. ${ }^{11}$ Intestinal sensory and motor functions are also maintained by fermentation products and neuroendocrine factors released by intestinal microflora. ${ }^{18,19}$ Therefore it promotes feed tolerance, favours growth, offers protection against sepsis and NEC.

In this trial, $79 \%$ of infants in probiotics and $83 \%$ in controls were delivered by lower uterine caesarean section (LUCS) and it contributes to altered microbial flora in premies. ${ }^{20,21}$

Feeding tolerance was found better in probiotics group (Table-II). This finding was comparable with most other studies. ${ }^{22,23}$ Arelevant meta-analysis also concluded such improvement in gastrointestinal tolerance. ${ }^{24}$ Probiotic improves gastrointestinal motility in both upper and lower gut which probably accounted for improvement in feed tolerance in probiotic supplemented group. Improved gastrointestinal motility was evidenced by electrogastrographic study $(E G G)^{25}$ where it was shown that gastric emptying rate and reduced fasting antral areas were increased in probiotic supplemented preterm newborns. The underlying mechanism was related to production of short chain fatty acid (SCFA) that stimulated smooth muscle modulating cellular calcium influx in a canine in vitro model. ${ }^{26}$ In the large intestine they might inhibit peristaltic activity and stimulate tonic activity. Through a humoral pathway involving polypeptide $Y Y$, ileal and colonic SCFAs modified upper motility by inducing relaxation of the proximal stomach, lower esophageal sphincter, and reducing gastric emptying. ${ }^{27}$ The role of SCFA might be to coregulate the motility of the upper intestine. One of the beneficial effects exerted by probiotics is stimulation of short chain fatty acids (SCFAs).

Probiotics did not exert significant improvement on weight of study group. Most other studies also demonstrated similar results. ${ }^{23,25,28}$ However one study from Japan reported improved weight gain and feed tolerance when Bifidobacterium breve was given to preterm infants. ${ }^{29}$

Weight gain in the sick newborns are affected by many coexistent morbidities as well as provision for total parental supplementation and/ or breast milk 
fortifier which possibly affected the weight pattern in both groups in that study.

As regards to hospital stay probiotics supplementation reduced hospital stay significantly (Table-III). Early attainment of full enteral feed, possibly contributed to shorter hospital stay in the probiotic group. Similar finding was demonstrated by other studies. ${ }^{30}$

\section{Conclusion:}

Probiotic supplementation in preterm low birth weight babies improves feed tolerance and decreases hospital stay but does not affect weight gain .

\section{References:}

1. Morley R, Lucas A. Influence of early diet on outcome in preterm infants. Acta Paediatr Suppl 1994; 405:123-126.

2. Blencowe $H$, Cousens $S$, Oestergaard $M Z$, Chou D, Moller AB, Narwal R, et al. National, regional, and worldwide estimates of preterm birth rates in the year 2010 with time trends since 1990 for selected countries: a systematic analysis and implications. Lancet 2012; 379 : 2162-72.

3. National Low Birth Weight Survey of Bangladesh, 2003-2004. UNICEF: Bangladesh Bureau of Statistics 2005 .

4. Guarner F., Malagelada JR. Gut flora in health and disease. Lancet 2003; 361: 512-19.

5. Orrhage K, Nord CE. Factors controlling the bacterial colonization of the intestine in breastfed infants. Acta Paediatr Suppl 1999; 88: 47-57.

6. Panigrahi P, Gupta S and Gewolb IH and JR JGM. Occurrence of necrotizing enterocolitis may be dependent on patterns of bacterial adherence and intestinal colonization: studies in Caco-2 tissue culture and weanling rabbit models. Pediatr Res 1994; 36:115-21.

7. Sudo N, Sawamura S and Tanaka R. The requirement of intestinal bacterial flora for the development of an IgE production system fully susceptible to oral tolerance induction. J Immunol 1997;157:1739-45.

8. Björkstén B, Naaber P, Sepp E and Mikelsaar. The intestinal microflora in allergic Estonian and Swedish 2-year-old children. Clin Exp Allergy 1999; 29:342-46.
9. Famularo G, Moretti S, Marcellini S. Stimulation of immunity by probiotics. In: Fuller R, editor. Probiotics: therapeutic and other beneficial effects. London: Chapman and Hall; 1997. P. 133-181.

10. Reid G, Howard J, Siang Gan B. Can bacterial interference prevent infection? Trends Microbiol 2001; 9: 424-28.

11. Hamzaoui N, Pringault E. Interaction of microorganisms, epithelium, and lymphoid cells of the mucosa-associated lymphoid tissue. Ann NY Acad Sci 1998; 17: 65-74.

12. Schwiertz A, Gruhl B, Löbnitz M, Michel P, Radke M, Blaut M. Development of the intestinal bacterial composition in hospitalized preterm infants in comparison with breast-fed, full-term infants. Pediatr Res 2003; 54: 393-99.

13. Goldmann DA, Leclair J, Macone A. Bacterial colonization of neonates admitted to an intensive care environment. J Pediatr 1978; 93:288-93.

14. FAO, 2001. Health and Nutritional Properties of Probiotics in Food including Powder Milk with Live Lactic Acid Bacteria.

15. Metchnikoff E. Editor P. Chalmers Mitchell. The prolongation of life. Optimistic studies. G.P. Putnam's Sons in New York \&, London, Knickerbocker press 1908.

16. Millar M, Wilks M, Costeloe K. Probiotics for preterm infants? Arch Dis Child Fetal Neonatal Ed 2003 ; 88 : 354-58.

17. Singh SA, Dutta S, Narang A. Predictive Clinical Scores for Diagnosis of Late Onset Neonatal Septicemia. Journal of Tropical Pediatrics 2003; 49: 235-39.

18. Rondeau MP, Meltzer K, Michel KE, McManus CM, Washabau RJ. Short chain fatty acids stimulate feline colonic smooth muscle contraction. J Feline Med Surg 2003;5:167-73.

19. Cherbut C. Motor effects of short-chain fatty acids and lactate in the gastrointestinal tract. Proc Nutr Soc 2003; 62:95-99.

20. Abeywardana, 2009. Report of the Australian and New Zealand Neonatal Network 2006. ANZNN.

21. Lubetzky R. Mode of delivery and neonatal hematocrit. Am J Perinatol 2000; 17 : 163-65. 
22. Rouge $\mathrm{Cm}$, Piloquet $\mathrm{H}$, Butel $\mathrm{M} \mathrm{J}$, Berger $\mathrm{B}$, Rochat F, Ferraris L, et al. Oral supple-mentation with probiotics in very-low-birth-weight preterm infants: a randomized, doubleblind, placebocontrolled trial. Am J Clin Nutr 2009; 89 :182835.

23. Braga TD, Silva GAP, Lira PIC. Efficacy of Bifidobacterium breve and Lactobacillus casei oral supplementation on necrotizing enterocolitis in very-low-birth-weight preterm infants: a doubleblind, randomized, controlled trial. Am J Clin Nutr 2011; 93: 81-86.

24. Deshpande G, Rao S, Patole S. Probiotics for prevention of necrotising enterocolitis in preterm neonates with very low birthweight: a systematic review of randomised controlled trials. Lancet 2007; 369 : 1614-20.

25. Indrio F, Riezzo G, Raimondi F, Bisceglia M, Cavallo L, Francavilla R. The Effects of Probiotics on Feeding Tolerance, Bowel Habits, and Gastrointestinal Motility in Preterm Newborns. J Pediatr 2008; 152 : 801-06.

26. McManus C M, Michel K E, Simon D M, Washabau RJ. Effect of short chain fatty acids on contraction of smooth muscle in the canine colon. Am J Vet Res 2002; 63:295-300.

27. Labayen I, Forga L, González A, LenoirWijnkoop I, Nutr R, Martínez JA. Relationship between lactose digestion, gastrointestinal transit time and symptoms in lactose malabsorbers after dairy consumption. Aliment Pharm Therap 2001; 15: 543-49.

28. Underwood MA, Salzman $\mathrm{NH}$, Bennett $\mathrm{SH}$, et al. A Randomized Placebo-controlled Comparison of 2 Prebiotic/ Probiotic Combinations in Preterm Infants: Impact on Weight Gain, Intestinal Microbiota, and Fecal Short-chain Fatty Acids. Journal of Pediatric Gastroenterology and Nutrition 2009 ; 48 : 216-25.

29. Kitajima $H$, Sumida $Y$, Tanaka R , Yuki N, Takayama H, Fujimura M. Early administration of Bifidobacterium breve to preterm neonates: randomised control trial. Arch Dis Child 1997; 76: 101-07.

30. Samanta M, Sarkar M, Ghosh,P, Ghosh J K, Sinha M K, Chatterjee S. Prophylactic Probiotics for Prevention of Necrotizing Enterocolitis in Very Low Birth Weight Newborns. Journal of Tropical Pediatrics 2008; 55: 128-31. 